\title{
Integrating Information and Communication Technologies in English for Specific Purposes
}

\author{
Nooruddin \\ University of Gujrat \\ Correspondence concerning this article should be addressed to Nooruddin Din, University of Gujrat, \\ Jalalpur Jattan Road, Gujrat, Punjab 50700, Pakistan. E-mail: noor.zangi1@gmail.com \\ Musarat Yasmin \\ University of Gujrat \\ Correspondence concerning this article should be addressed to Nooruddin Din, University of Gujrat, \\ Jalalpur Jattan Road, Gujrat, Punjab 50700, Pakistan.E-mail: musarat.yasmin@uog.edu.pk
}

\begin{abstract}
The tenth volume of the book 'Integrating Information and Communication Technologies in English for Specific Purposes', edited by Dr. Rosa Muñoz-Luna and Dr. Lidia Taillefer, was published in 2018 by Springer International Publishing AG Switzerland.
\end{abstract}

Many books have been written on the subject of English for Specific Purposes (ESP) since the emergence of the concept in the early1960s but the present book is unique in its approach as it is an effort to digitalize the various aspects of ESP, thereby widening the scope and vision of ESP practitioners and learners. The book provides research-based practical knowledge from professional experts on the incorporation of modern means of information technology to boost the efficacy level of teaching and learning of the English language. It provides insights related to ESP, EAP (English for Academic Purposes), and EOP (English for Occupational Purposes) in contexts where English is used or taught as a second or a foreign language.

The book consists of three sections. Section One dwells upon the pedagogical principles in English for specific purposes, Section Two focuses on English for academic purposes, and the third section deals with English for occupational purposes. The foreword by Dr. Augustyn Surdyk stimulates the interest of the readers by highlighting the features and significance of information and communication technologies (ICTs) and ludology in the teaching and learning of English language. As the book implies, ICTs include the internet, emails, audio \& video live communication, and other technologies facilitating face-to-face interaction; whereas, the discipline of ludology refers to game studies. Ludology is equally important in maintaining the effectiveness of learning. Both ludic techniques and ICTs refer to gamification, which is used to 'increase engagement, efficiency and positive attitudes' (p. vii).

The introduction contains a detailed overview of the book and subsequently gives some glimpses into the 
various chapters. The editors explain that 'ESP' is an umbrella term. They show that it can incorporate the latest technologies in the academic field as well as in occupational settings. They assert that 'innovation' can only be achieved in ESP, EAP, or EOP through the 'proficient use of technology' (p.1). It is underlined that teachers and professionals can make teaching and learning innovative through practical training on a continuous basis. The prime focus of this book is to enable language users and practitioners from all domains of learning to develop innovative methods based on online teaching and learning tools.

Section One of the book consists of three chapters and presents a panoramic picture of different aspects of ESP in the perspective of modern requirements. Chapter One, headlined "Integrating Technology in ESP: Pedagogical Principles and Practice" by Li Li, highlights the advantages and restrictions of technologies within ESP. The author suggests that the new technologies in ESP are not flourishing due to a lack of computer literacy. The information technologies allow ESP students to experience real life situations, enhancing their communicative competence. Likewise, computer-mediated communications (CMC), like Skype or email also play a vital role in ESP. According to Li, "the Internet is considered an authentic resource for natural, context-rich and culturally specific materials.” (p. 12). These technologies not only provide a proper environment for interaction and selfdirected learning but also motivate and engage learners. Proceeding further, Li then clarifies five principles for integrating technologies into ESP. He then provides examples related to corpus and web-based materials. Indeed, this detailed discussion introduces new trends in the field of ESP. Conforming to Li, Nesi, (2013) also integrates corpus studies from the various domains of ESP such as EAP and EOP. She illustrates the various implications of corpora in ESP. Similarly, Bloch, (n.d.) suggests the importance of incorporation of blogs, Facebook pages, Twitter, email, etc. in the process of teaching and learning. He states that "the experiences with these technologies that students bring from both inside and outside the classroom may be invaluable in their future careers." (p. 387).

Chapter Two, titled "Using Technology in the Teaching of ESP: Some Reflections Based on Practice" by Sandra Stroo, Rosa Muñoz-Luna, and Antonio Jurado-Navas, provides a detailed discussion on the use of some basic computer software and applications in ESP classroom settings. The authors not only focus on software and technologies but also elaborate on their pedagogical implications. They reassert that practice of the learning material in its proper context is necessary for language acquisition. For teaching EAP at higher levels, the researchers suggest that "technology should provide a shared virtual and blended-learning space where collective learning can be facilitated." (p.29). The chapter further highlights the importance of software like 'Turnitin' and 'Ephorus' for managing plagiarism free writing. Likewise, the importance of 'Clicker (Educlick)', smartphones, movie clips, etc. is also under scrutiny. Thus, the chapter is full of information that may encourage readers to think of implementing modern technologies when teaching ESP.

Chapter Three in Section One headlined “Independent ESP Learners: The Case for Blended Learning” is authored by Renia López-Ozieblo. The researcher suggests that the learning process can be made effective through "...a methodology that combines a face-to-face approach with the use of information and communications technology (ICT)" (p.37). She also recommends to maintain social interaction, which plays a key role in the process of second language acquisition (SLA). The chapter is filled with many examples of learning language through online social interaction. Online courses and their analysis, particularly 'MOOCs', are also discussed. Last but not least, the author focuses on highly effective technological and pedagogical approaches for meeting the already planned objectives.

Section Two enriches readers with deep insights regarding the use of internet resources for developing academic essay writing skills. This section is essentially aimed at language teachers at high school or university levels. Section Two is comprised of four chapters. It starts with a chapter entitled "The Internet as a Pedagogical Tool in the Writing Process: A Research-Based Approach” by Mercedes Díez-Prados and Ana Belén Cabrejas-Peñuelas. The chapter offers a detailed discussion on the use of internet applications, i.e. Web 2.0 for facilitating academic writing tasks and many practical examples are given. The authors go over all of the key stages of academic writing and a number of corresponding websites. Although internet technologies seem quite beneficial for those who are computer literate and study in well-equipped settings, such techniques are not that efficient in locations where there are no appropriate computer facilities or internet access.

Chapter Two, titled “Learning Management Systems for Teaching at the University Level: Students' Attitudes and Real Usage in the Classroom" by Antonio Jurado-Navas, deals with students' behaviour in the computer- 
enhanced environment for learning language. The author analyses the efficacy of 'learning management systems' (LMSs) and students' perceptions and attitudes concerning these systems. The chapter dwells on removing the anxiety of students when learning second languages. The author contends that the LMS and the teacher both have a role to play in soothing students' anxiety. The author puts forward a research-based study on the reactions and behaviors of undergraduate students in the context of online management procedures. The data were collected through a questionnaire and showed that most university teachers use online systems to upload study materials for their students. It is also noted that students prefer small-group interactive sessions that impart information rather than big-group sessions focusing on errors. This chapter enables teachers to frame their classroom pedagogy accordingly.

In Chapter Three (Section 2), headlined "English for Academic Purposes: A Proposal to Improve Listening Skills of Education Students”, Ana María Ramos-García highlights different reasons for poor listening skills and presents strategies to enhance them. The author also shares her research on developing anxiety-free listening environments. She emphasizes the importance of using online listening materials such as podcasts and other web-accessible materials. She suggests listening strategies and recommends learners to maintain their listening record in online diaries for later discussion. This programme reduces the anxiety level of students as inadequate listening skills lead to stress in the classroom.

The last chapter of Section Two, "Multimedia EAP Learning in Virtual Reality: Second Life in an English Department" by Lan Li, presents her research based on investigations into teaching English using Second Life, a 3D simulator where students and their teacher can interact in English like videogame characters. She agrees with Mayer's cognitive theory of multimedia learning, which asserts that "people build mental representations from words and pictures" (Mayer, 2005, p.109). The data show that learning English in a Second Life setting is highly interactive, interesting, and entertaining.

The strategies mentioned in these chapters of Section Two are highly effective, but their limitations cannot be ignored. Such technologies are not easily accessed in some developing countries and locations. Students there may even be unaware of their existence.

Section Three of the book covers the ins and outs of English for Occupational Purposes. This section provides a deeper understanding to teachers and instructors who are willing to design language courses for occupational purposes. Chapter One here is headlined "ESP and Free Online Dictionaries" and authored by Pedro A. FuertesOlivera. The researcher emphasizes the use of free online dictionaries, especially for business and economic studies. He situates the concept of ESP in the context of a Spanish university and suggests using Wikipedia and other specialized dictionaries to gain knowledge related to a specific field.

Chapter Two, "Translation, Virtual Environments and ICT Tools for Achieving Competence in Language for Specific Purposes" by Encarnación Postigo-Pinazo and Concepción Mira-Rueda, critically evaluates the authenticity of translation procedures for achieving complete competence in language use for specific purposes. The authors suggest skills and strategies to improve translations. They present research carried out in the medical care field. The essay also looks into competence levels of translators and interpreters in the Spanish context. As Spain is famous for medical tourism, the authors mention that "in medical tourism, citizens of highly developed nations bypass services offered in their own communities and travel to less developed areas of the world for medical care (p.146).

Chapter Three, titled "A Business English Course in the Digital Era: Design and Analysis" by Lidia Taillefer, puts forward a detailed overview of the complete course design for business English. The author strongly recommends integrating online resources to make the course more productive. The chapter also highlights the limitations and advantages of blended courses. Like the previous chapter, the last chapter of this book, "Online Course Design for Translation into English" by Leah Leone, also gives insights into planning and developing an online course for teaching translation skills. She analyses her learners' needs and then incorporates activities based on the latest technologies into training translators to become professionally competent.

This brief overview of the chapters should clearly demonstrate that this book is a unique gift for English language teachers, learners, and researchers who want to innovate their classrooms by incorporating Information and Communication Technologies (ICTs) within the fields of ESP, EAP, and EOP. The contents of this book are based 
on the practical experiences of the authors. All of the contributors represent their full professional expertise and motivate teachers and learners to find technical solutions related to the problems in ESP, EAP, or EOP. Even an average computer user can get access to new online learning resources and obtain the maximum benefit. But at the same time, traditional teaching methods cannot be simply set aside. The integration of traditional approaches to language teaching with modern technologies may produce better outcomes. Furthermore, some of the abovementioned technologies may not be applicable in all contexts; only highly skilled teachers and learners can use them without reservation.

This book is a valuable asset for the ESP researchers, teachers, students, and instructors. The core contents of these chapters will certainly help to make the teaching and learning of English an energizing experience.

\section{Conflict of Interest}

The authors declare that they have no conflict of interest.

\section{References}

Bloch, J. (2013). Technology and ESP. In B. Paltridge, \& S. Starfield (Eds.), The Handbook of English for Specific Purposes (pp.385-40). Chichester, UK: John Wiley \& Sons, Inc.

Nesi, H. (2013). ESP and Corpus Studies. In B. Paltridge \& S. Starfield (Eds.), The Handbook of English for Specific Purposes (pp. 407-426). Chichester, UK: John Wiley \& Sons, Inc. 